\title{
Novel Phosphodiesterase 4 Inhibitor FCPR03 Alleviates Lipopolysaccharide-Induced Neuroinflammation by Regulation of the cAMP/PKA/CREB Signaling Pathway and NF- $\kappa$ B Inhibition
}

\author{
Zheng-Qiang Zou, Jia-Jia Chen, Hong-Fang Feng, Yu-Fang Cheng, Hai-Tao Wang, \\ Zhong-Zhen Zhou, Hai-Biao Guo, Wenhua Zheng, and Jiang-Ping Xu \\ Department of Neuropharmacology and Novel Drug Discovery, School of Pharmaceutical Sciences, Southern Medical University \\ (Z.-Q.Z., J.-J.C., H.-F.F., H.-T.W., Z.-Z.Z., J.-P.X.), Central Laboratory, Southern Medical University (Y.-F.C., J.-P.X.), and \\ Modern Chinese Medicine Research Institute of Hutchison Whampoa Guangzhou Bai Yunshan Chinese Medicine Co., Ltd., \\ Guangzhou, (H.-B.G.); and Faculty of Health Sciences, University of Macau, Taipa, Macau (W.Z.), China
}

Received December 17, 2016; accepted April 20, 2017

\begin{abstract}
Overactivation of microglia contributes to the induction of neuroinflammation, which is highly involved in the pathology of many neurodegenerative diseases. Phosphodiesterase 4 (PDE4) represents a promising therapeutic target for anti-inflammation; however, the dose-limiting side effects, such as nausea and emesis, have impeded their clinic application. FCPR03, a novel selective PDE4 inhibitor synthesized in our laboratory, shows little or no emetic potency; however, the anti-inflammatory activities of FCPRO3 in vitro and in vivo and the molecular mechanisms are still not clearly understood. This study was undertaken to delineate the anti-inflammatory effects of FCPR03 both in vitro and in vivo and explore whether these effects are regulated by PDE4-mediated signaling pathway. BV-2 microglial cells stimulated by lipopolysaccharide (LPS) and mice injected i.p. with LPS were established as in vitro and in vivo
\end{abstract}

models of inflammation. Our results showed that FCPR03 dose dependently suppressed the production of tumor necrosis factor $\alpha$, interleukin-1 $\beta$, and interleukin-6 in BV-2 microglial cells treated with LPS. The role of FCPRO3 in the production of proinflammatory factors was reversed by pretreatment with protein kinase $\mathrm{A}(\mathrm{PKA})$ inhibitor $\mathrm{H} 89$. In addition, FCPR03 reduced the levels of proinflammatory factors in the hippocampus and cortex of mice injected with LPS. Our results further demonstrated that FCPRO3 effectively increased the production of CAMP, promoted CAMP response element binding protein (CREB) phosphorylation, and inhibited nuclear factor $\kappa \mathrm{B}$ (NF- $\kappa \mathrm{B}$ ) activation both in vitro and in vivo. Our findings suggest that FCPRO3 inhibits the neuroinflammatory response through the activation of CAMP/PKA/CREB signaling pathway and NF- $\kappa \mathrm{B}$ inhibition.

\section{Introduction}

Increasing evidence suggests that neuroinflammation exacerbates many neurodegenerative diseases, including Alzheimer disease, Parkinson disease, and depression (Wilms et al., 2003; Maes et al., 2009; Philips and Robberecht, 2011; Eikelenboom et al., 2012; Blandini, 2013; Heneka et al., 2014), mainly through microglia activation, which results in the production of various proinflammatory cytokines and subsequent neuronal cell death (Pais et al., 2013; Gonzalez et al., 2014). In recent years, the strategy for inhibiting microgliamediated inflammation has attracted increasing attention and may provide a promising therapy for neuroinflammatory and neurodegenerative diseases.

This work was supported by the National Science and Technology Major Projects of China for Major New Drug Innovation and Development (Grant 2012ZX09J1211003C) and the National Natural Science Foundation of China (Grant 81373384 and 81503043) Science and Technology Planning Project of Guangdong Province (Grant 2012B050500005 and 2015B020211007).

https://doi.org/10.1124/jpet.116.239608.
Microglia, the resident immune cells of the central nervous system (CNS), constitute a double-edged sword for the CNS, with both beneficial and detrimental effects. It is well known that microglia can phagocytize invading pathogens and cellular debris (Neher et al., 2013), secrete neurotrophic factors that regulate the microenvironment (Czeh et al., 2011), and even repair injured tissues; but overactivated microglia release various proinflammatory cytokines, such as tumor necrosis factor- $\alpha$ (TNF- $\alpha$ ), interleukin-1 $\beta$ (IL-1 $\beta$ ), and interleukin-6 (IL-6) (Rawji et al., 2016). Multiple clinical studies reveal that microglia overactivation and elevated levels of proinflammatory cytokines are found in the brains of patients with neurodegenerative diseases (McGeer and McGeer, 2013; Heneka et al., 2014).

Lipopolysaccharide (LPS), a major outer membrane component in Gram negative bacteria, potently induces inflammation, activation of microglial cells, and an increase the expression of proinflammatory cytokines, such as TNF- $\alpha$, IL-1 $\beta$, and IL-6 (Norden et al., 2016). TNF- $\alpha$ can activate the

ABBREVIATIONS: CNS, central nervous system; CREB, CAMP response element binding protein; ELISA, enzyme-linked immunosorbent assay; FCPR03, or N-isopropyl-3-(cyclopropylmethoxy)-4-difluoromethoxy benzamide (10j); IL-1 $\beta$, interleukin-1 $\beta$; IL-6, interleukin-6; LPS, lipopolysaccharide; MTT, tetrazolium salt 3-[4, 5-dimethylthiazol-2-yl]-2, 5-diphenyltetrazolium bromide; NF- $\kappa$ B, nuclear factor $\kappa$ B; PDE4, phosphodiesterase 4; PBS, phosphate-buffered saline; PKA, protein kinase A; TNF- $\alpha$, tumor necrosis factor- $\alpha$. 
nuclear transcription factor- $\kappa \mathrm{B}(\mathrm{NF}-\kappa \mathrm{B})$ pathway, which in turn leads to cell apoptosis (Brenner et al., 2015). IL-1 $\beta$, an important contributor in brain inflammation, is significantly increased in patients with neurodegenerative diseases (Kaushal et al., 2015). IL-6 upregulation may increase the levels of harmful mediators in the vascular endothelium, mediating inflammatory cascades and leading to the aggravation of neurodegenerative diseases (Rothaug et al., 2016). It is well established that $\mathrm{NF}-\kappa \mathrm{B}$ regulates the expression of proinflammatory cytokines in LPS-induced microglial cells (Kopitar-Jerala, 2015), suggesting that inhibiting NF- $\mathrm{B}$ may be an effective therapeutic target for inflammatory diseases.

As the predominant modulator of the cAMP signaling cascade, phosphodiesterase 4 (PDE4) represents a promising target for modulating the immune function. Numerous studies have shown that PDE4 inhibition increases the intracellular availability of cAMP and actives the cAMP)/ protein kinase A (PKA)/cAMP response element binding protein (CREB) signaling pathway (McGirr et al., 2016; Wang, et al., 2016). Reports document that PDE4 inhibitors are widely used pharmaceutical agents with a broad range of anti-inflammatory properties. The PDE4 inhibitor rolipram is suggested to prevent leukocytes accumulation, airway hyper-responsiveness, and cytokine release (Ikemura et al., 2000). Furthermore, roflumilast inhibits lung inflammation in mildly asthmatic patients with allergen challenge (Gauvreau et al., 2011). Recently, another selective PDE4 inhibitor, apremilast, is attributed to have therapeutic effects in psoriatic arthritis and plaque psoriasis (Papp et al., 2012; Schett et al., 2012). Recent studies also reveal that cAMP/ PKA/CREB signaling is closely involved in neuroinflammatory responses (Wang, et al., 2012). Preclinical findings suggest therapeutic efficacy for PDE4 inhibitors in a wide range of neurodegenerative diseases where neuroinflammation plays an important role, including Alzheimer disease (Gong et al., 2004), Parkinson disease (Blandini, 2013), major depressive disorder (Plattner et al., 2015), and multiple sclerosis (Gonzalez-Garcia et al., 2013).

FCPR03, or N-isopropyl-3-(cyclopropylmethoxy)-4difluoromethoxy benzamide (10j), displays a high PDE4 enzymes selectivity with a low $\mathrm{IC}_{50}$ of $60 \mathrm{nM}$ (Fig. 1A). In addition, our previous studies also found that FCPR03 inhibited LPS-induced TNF- $\alpha$, iNOS, and COX-2 expression in microglial cells and did not cause emesis in beagle dogs during the 180-minute observation period at $0.8 \mathrm{mg} / \mathrm{kg}$ (Zhou et al., 2017), suggesting that FCPR03 not only has good antiinflammation property, but it also has less emetic potency than other PDE4 inhibitors, such as rolipram; however, the underlying mechanisms are still not clearly understood. Although FCPR03's positive anti-inflammatory effect has been preliminarily demonstrated at the cellular level, its antiinflammatory effect still needs to be verified from in vivo studies; additionally, whether its anti-inflammatory effect is mediated through the inhibition of PDE4 enzyme, and the subsequent activation of cAMP/PKA/CREB signaling pathway is unclear. In the present study, the effects of FCPR03 in LPS-induced inflammation both in vitro and in vivo were evaluated. Furthermore, whether the possible anti-inflammatory effects of this compound were associated with the cAMP/PKA/CREB signaling cascade and NF- $\kappa \mathrm{B}$ inhibition were assessed.

\section{Materials and Methods}

Drugs. Lipopolysaccharide (LPS) from Escherichia coli strain 055: B5 (Sigma-Aldrich Corp., St. Louis, MO), rolipram, 4-[3-(cyclopentyloxy)-4methoxyphenyl]-2-pyrrolidinone (Enzo Life Sciences, Farmingdale, NY), and the PKA inhibitor H89, N-[2-(p-bromocinnamylamino)ethyl]-5isoquinolinesulfonamide $\cdot 2 \mathrm{HCl}$ hydrate (Beyotime Institute of Biotechnology, Nanjing, China) were used. The drugs were prepared freshly before use. All other chemicals used were of analytical grade.

Cell Culture. BV-2 microglial cells, an immortalized murine microglial cell line, were a gift from the Cell Bank of the Chinese Academy of Sciences (Shanghai, China). They were maintained in Dulbecco's modified Eagle's medium containing 10\% fetal bovine serum and antibiotics (100 IU/ml penicillin and $100 \mathrm{mg} / \mathrm{ml}$ streptomycin) at $37^{\circ} \mathrm{C}$ in a $5 \% \mathrm{CO}_{2}$ incubator. At about $80 \%-90 \%$ confluency, cells were split twice a week with $0.25 \%$ trypsin.

Cell Viability Assay. Cell viability was evaluated by the tetrazolium salt 3-[4, 5-dimethylthiazol-2-yl]-2, 5-diphenyltetrazolium bromide (MTT; Sigma, St. Louis, MO) assay (Zhou et al., 2017). Briefly, BV-2 microglial cells $\left(8 \times 10^{3}\right.$ cells/well $)$ were seeded into 96 -well plates and pretreated with various concentrations of FCPR03 for 1 hour before stimulation with LPS $(1 \mu \mathrm{g} / \mathrm{ml})$ for 24 hours. After treatment, the medium was removed, and cells were incubated with MTT $(0.5 \mathrm{mg} / \mathrm{ml})$ for 4 hours at $37^{\circ} \mathrm{C}$. The resulting formazan crystals were solubilized with DMSO, and absorbance was measured at $570 \mathrm{~nm}$ on a microplate reader (Synergy HT; BIOTEK, Broadview, IL).

Animals. Male C57BL/6 mice ( 8 weeks old, 20-25 g) were obtained from the Laboratory Animal Centre of Southern Medical University (Guangzhou, China) and acclimated in the facility for 1 week before the experiments. They were housed eight per cage in standard environmental conditions $\left(22 \pm 2{ }^{\circ} \mathrm{C}\right.$; humidity. $60 \% \pm 5 \%$; 12 -hour light/dark cycle with lights on at 7:00), with access to food and water ad libitum. Experimental procedures were conducted between 8:30 and 16:30. All experiments using animals were carried out in accordance with the National Institutes of Health (NIH) Guide for the Care and Use of Laboratory Animals 2011, and this study was approved by the Laboratory Animal Ethics Committee of Southern Medical University.

Mouse Model of Neuroinflammation. LPS was administered i.p. to induce neuroinflammation in mice, as previously described (Yuan et al., 2016). Mice were randomly divided into five experimental groups ( $n=8$ ): control (vehicle, $10 \mathrm{ml} / \mathrm{kg}$ ), LPS (vehicle, $10 \mathrm{ml} / \mathrm{kg}$ ), LPS + FCPR03 (FCPR03 0.5 and $1 \mathrm{mg} / \mathrm{kg}$, respectively), and positive control (rolipram $1 \mathrm{mg} / \mathrm{kg}$ ) groups. Drugs were intragastrically administered once daily for 7 consecutive days. At 7 days, mice were injected i.p. with saline or LPS $(1.2 \mathrm{mg} / \mathrm{kg}) 30$ minutes after the last drug administration. Then, the animals were sacrificed by cervical dislocation 24 hours after saline or LPS challenge. The hippocampus and cortex were isolated immediately and stored at $-80^{\circ} \mathrm{C}$ for further biochemical analysis.

Novel Object Recognition Test. The test was carried out as described previously (Zhang et al., 2014). On day 6 after FCPR03 administration, each mouse was allowed to move freely in a white box $(60 \times 60 \times 15 \mathrm{~cm})$ for 5 minutes to habituate to the surroundings, 24 hours later, mice were individually placed in the center of the box containing two identical objects located in two corners diagonal from each other. The time spent in exploring each object was recorded during a 5- minute period. Exploration was defined as touching or facing the object within a 2-cm distance, and 24 hours after LPS injection, the food intake and body weight changes were measured; then mice were tested for memory using the same procedure except one of the objects was replaced with one of a different shape and color. The recognition index was expressed by the ratio $\mathrm{TN} /(\mathrm{TF}+\mathrm{TN})$, where $\mathrm{TF}=$ time spent exploring the familiar object and $\mathrm{TN}=$ time spent exploring the novel object.

Assessment of Cytokine and cAMP Levels. TNF- $\alpha$, IL- $1 \beta$, and IL-6 levels were determined by using enzyme-linked immunosorbent assay (ELISA) kits purchased from Boster (Wuhan, China). Cytokine 

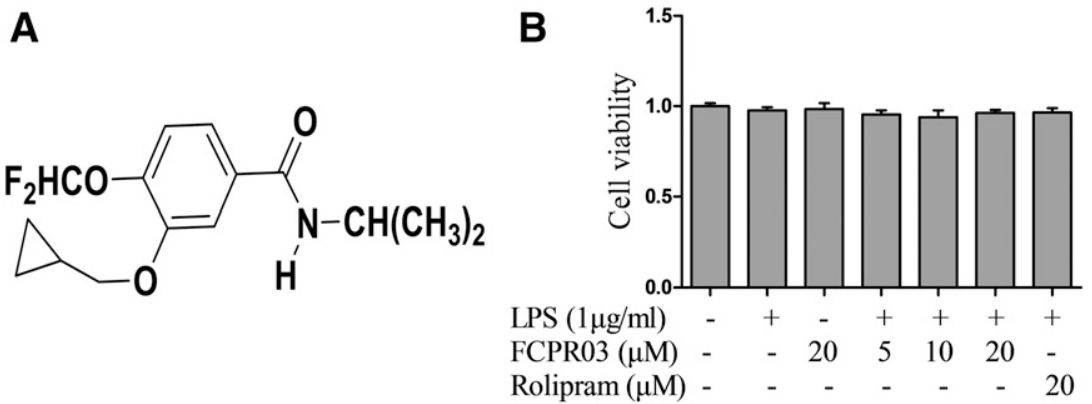

Fig. 1. Chemical structure of FCPR03 and BV-2 microglial cells' viability after pretreatment with FCPR03. Chemical structure of FCPR03 (A). BV-2 microglial cells were pretreated with various concentrations of FCPR03 $(5,10$, and $20 \mu \mathrm{M})$ or rolipram $(20 \mu \mathrm{M})$ for 1 hour before stimulation with LPS $(1 \mu \mathrm{g} / \mathrm{ml})$ for 24 hours. Cell viability was detected by the MTT assay (B). Values are mean \pm S.E.M. $(n=6$ /group $)$. amounts in $100-\mu$ l samples were determined according to the manufacturer's protocol. Quantitative determination of cAMP levels was performed by ELISA (cAMP assay kit; R \& D Systems, Minneapolis, MN) according to the manufacturer's instructions. Relative cAMP levels were normalized to total protein. All samples and standards were assayed in duplicate.

Immunofluorescence Staining. The nuclear localization of $\mathrm{NF}-\kappa \mathrm{B}$ p65 was examined by indirect immunofluorescence assay (Kim et al., 2015). BV-2 microglial cells $\left(1 \times 10^{6}\right.$ cells/well $)$ were cultured on sterile 15 -mm coverslips in 24 -well plates for 12 hours and pretreated with FCPR03 $(20 \mu \mathrm{M})$ for 1 hour. After stimulation with LPS for 1 hour, cells were fixed with $4 \%$ paraformaldehyde in phosphate-buffered saline (PBS), permeabilized with $0.2 \%$ Triton $\mathrm{X}-100$ in PBS, and blocked with $5 \%$ bovine albumin V. Then, anti-NF$\kappa \mathrm{B}$ p65 monoclonal antibodies (1:100) (Cell Signaling Technology, Beverly, MA) were applied overnight at $4^{\circ} \mathrm{C}$, followed by 3 hours of incubation with Alexa 488-conjugated secondary antibodies at $4^{\circ} \mathrm{C}$. After three washes with PBS, the cell nuclei were counterstained with $1 \mathrm{mM}$ DAPI. Finally, the cells were visualized and photographed on a Nikon Instruments C2 Confocal Microscope (Nikon, Tokyo, Japan). Representative images were obtained from 16 high-power fields per sample.

Western Blot Analysis. Western blot procedures were performed as previously described (Zhou et al., 2017). In brief, brain tissues and microglial cell lysates were prepared using a modified RIPA buffer $(1 \times$ RIPA lysis buffer including $1 \%$ protease inhibitor cocktail and $1 \%$ phosphatase inhibitor cocktail). Total protein concentration was measured using a BCA protein assay kit (Thermo Scientific, Waltham, MA). Equal amounts of protein were separated by $10 \%-15 \%$ SDSPAGE), and proteins were transferred onto polyvinyldidene membranes (Millipore, Bedford, MA). After blocking in Tris-buffered saline with $0.1 \%$ Tween-20 (blocking buffer) containing $5 \%$ (w/v) nonfat milk for 1 hour at room temperature, the membranes were incubated overnight with specific primary antibodies at $4^{\circ} \mathrm{C}$. After three washes in Tris-buffered saline with $0.1 \%$ Tween- 20 , incubation was carried out with appropriate secondary antibodies for 3 hours at $4^{\circ} \mathrm{C}$. Detection was performed with the enhanced chemiluminescence reagent (ECL, Millipore), and protein bands were revealed by autoradiography. The following primary antibodies were used: anti-phospho-CREB (Cell Signaling Technology, Beverly, MA), anti-NF- $\kappa$ B p65 (Cell Signaling Technology), and rabbit anti-GAPDH polyclonal (Abcam, Cambridge, MA) and anti-histone H3 (Cell Signaling Technology) antibodies. GAPDH and H3 were used as loading controls. Densitometric analysis of protein bands was performed using the ImageJ Software (NIH). To assess NF- $\kappa$ B p65 translocation, nuclear and cytoplasmic extracts were prepared with nuclear and cytoplasmic protein extraction kit purchased from Beyotime Institute of Biotechnology (Nanjing, China).

Statistical Analysis. Data are expressed as mean \pm standard error of the mean (S.E.M.) and were assessed by one-way analysis of variance followed by Bonferroni's post hoc test. Statistical Package for the Social Sciences (SPSS, Armonk, NY) version 13.0 was used for statistical analyses. Graphs were plotted with the GraphPad Prism 5.0 software (GraphPad Software, La Jolla, CA). $P<0.05$ was considered statistically significant.

\section{Results}

Effect of FCPR03 on BV-2 Microglial Cells Viability. To rule out FCPR03 toxicity in microglia, BV-2 microglial cells were pretreated with FCPR03 and/or LPS to test cell viability using the MTT assay. Precisely, BV-2 microglial cells were pretreated with FCPR03 at 5, 10, and $20 \mu \mathrm{M}$, respectively, for 1 hour and incubated in the presence of LPS (1 $\mu \mathrm{g} / \mathrm{ml}$ ) for 24 hours. Our data showed that FCPR03 and/or LPS produced no toxicity at the tested concentrations $(P>0.05)$. Similar to FCPR03, the positive control rolipram $(20 \mu \mathrm{M})$ also showed no toxic effects on BV-2 microglial cells $(P>0.05)$ (Fig. 1B).

FCPR03 Inhibited Proinflammatory Cytokines Release in LPS-Stimulated BV-2 Microglial Cells. Since PDE4 is a potential therapeutic target for the limitation of inflammation, we aimed to assess whether FCPR03 inhibits the production of proinflammatory cytokines (TNF- $\alpha$, IL- $1 \beta$, and IL-6) in LPS-treated microglial cells. As shown in Fig. 2, A-C, treatment with LPS caused a significant increase in the production of TNF- $\alpha$, IL- $1 \beta$, and IL-6 in BV-2 microglial cells $(P<0.01)$; however, the levels of these proinflammatory factors in the supernatant were dramatically attenuated by FCPR03 at the dose of $10 \mu \mathrm{M}(P<0.05)$, and rolipram had a similar anti-inflammatory effect at $20 \mu \mathrm{M}$ with FCPR03 $(P<$ 0.01). Moreover, the anti-inflammatory effect of FCPR03 was almost blocked by the pretreatment with PKA inhibitor H89 (Fig. 2, D-F), indicating that the anti-inflammatory effect of FCPR03 is probably through upregulating the cAMP/PKA signaling pathway.

Effect of FCPR03 on cAMP/PKA/CREB Signaling in BV-2 Microglial Cells. To ensure whether the antiinflammatory effect of FCPR03 was mediated by cAMP/PKA/ CREB signaling pathway, we assessed the intracellular cAMP level in BV-2 microglial cells with ELISA assay. We found that FCPR03 alone could significantly enhance the level of intracellular cAMP in BV-2 microglial cells at $20 \mu \mathrm{M}(P<$ 0.05) (Fig. 3A). Whereas stimulation with LPS for 24 hours dramatically decreased the intracellular cAMP level in BV-2 microglial cells $(P<0.05)$, this effect was reversed by pretreatment with $20 \mu \mathrm{M}$ FCPR03 $(P<0.05)$ (Fig. 3B). Furthermore, our data also showed that FCPR03 promoted CREB phosphorylation in BV-2 microglial cells, an effect that peaks at 30 minutes $(P<0.05)$ (Fig. $4 \mathrm{~A})$, whereas the increased phosphorylation of CREB was also reversed by pretreatment with H89 $(P<0.05)$ (Fig. 4B). On the other hand, our results also revealed that pretreatment with $20 \mu \mathrm{M}$ FCPR03 could reverse the reduction of phosphorylated CREB induced by LPS (Fig. 4, C and D). Hence, our data demonstrate 

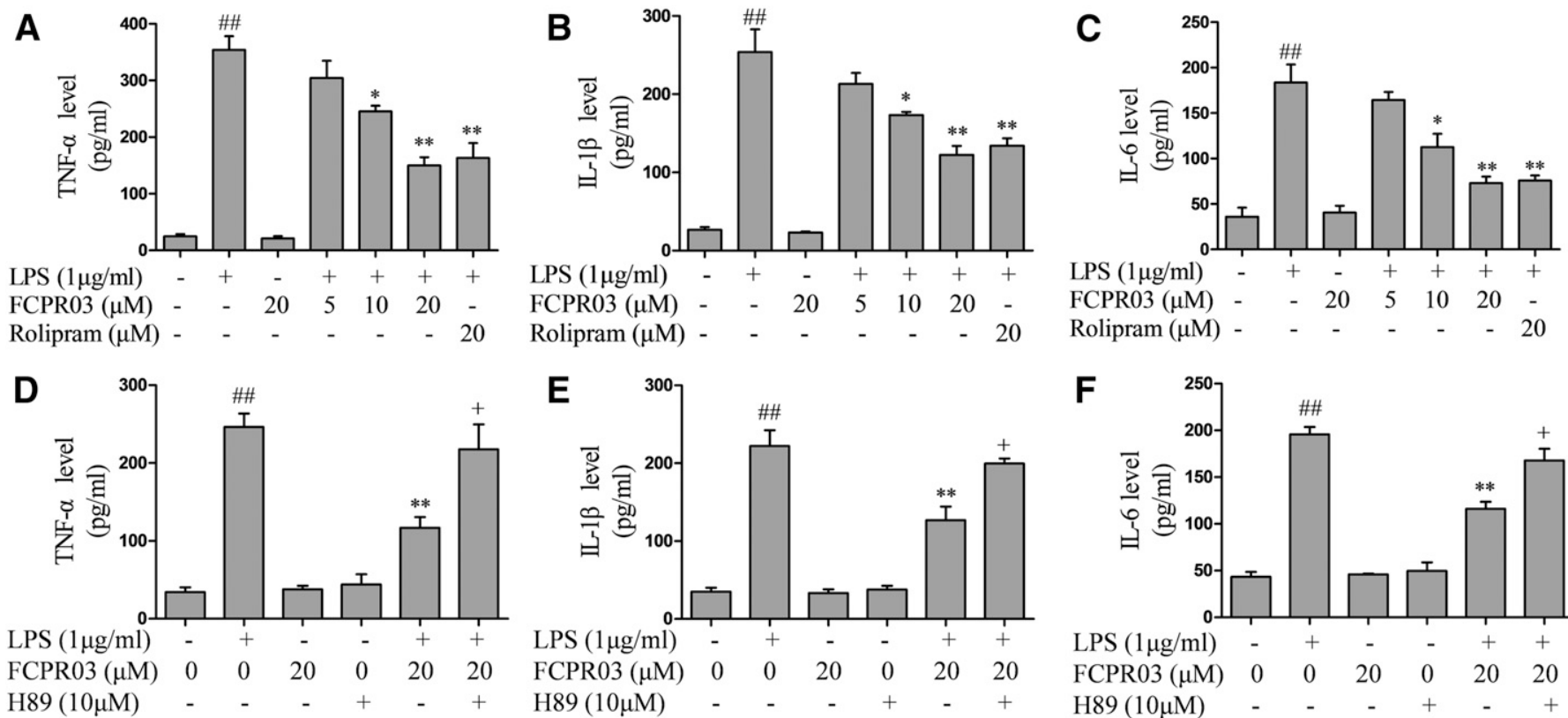

Fig. 2. The inhibition effects of FCPR03 on TNF- $\alpha$, IL-1 $\beta$, and IL-6 production in LPS-induced BV-2 microglial cells. BV-2 microglial cells were pretreated with various concentrations of FCPR03 $(5,10$, and $20 \mu \mathrm{M})$ or rolipram $(20 \mu \mathrm{M})$ for 1 hour in the presence of the selective PKA inhibitor H89 $(10 \mu \mathrm{M})$ for 40 minutes before stimulation with LPS $(1 \mu \mathrm{g} / \mathrm{ml})$ for 24 hours. Then, the levels of TNF- $\alpha$, IL- $1 \beta$, and IL-6 in cell-culture supernatants were measured with commercial ELISA kits. Data are expressed as mean \pm S.E.M. $\left(n=6\right.$ /group). ${ }^{\# \# ~} P<0.01$ compared with the control group; ${ }^{*} P<0.05,{ }^{* *} P<$ 0.01 compared with the LPS group; ${ }^{+} P<0.05$ compared with the LPS + FCPR03 $(20 \mu \mathrm{M})$ group.

that FCPR03 activates the cAMP/PKA/CREB signaling pathway, which subsequently suppresses the production of proinflammatory cytokines in LPS-induced BV-2 microglial cells.

Effect of FCPR03 on NF- $k B$ p65 Activation in LPSStimulated BV-2 Microglial Cells. Activation of the $\mathrm{NF}-\kappa \mathrm{B}$ plays an important role in regulating the expression of proinflammatory cytokines. To assess whether FCPR03 inhibited the activation of NF- $\kappa \mathrm{B}$ p65 under the condition of neuroinflammation, BV-2 microglial cells were treated with LPS $(1 \mu \mathrm{g} / \mathrm{ml})$ in the presence of FCPR03 $(20 \mu \mathrm{M})$ for 1 hour, and the activation of NF- $\kappa \mathrm{B}$ p65 was analyzed by Western blotting. As shown in Fig. 5A, LPS and FCPR03 did not alter protein expression of NF- $\kappa \mathrm{B}$ p65 in BV-2 cells. Whereas LPS promoted the translocation of $\mathrm{NF}-\kappa \mathrm{B}$ p65 from cytosol into nucleus, FCPR03 inhibited LPS-induced subcellular translocation. More interestingly, this effect of FCPR03 was blocked by pretreatment with $\mathrm{H} 89(P<0.05)$ (Fig. $5, \mathrm{~B}$ and C). Furthermore, immunofluorescence assay verified these findings (Fig. 5D). The data suggest that inhibition of the release of proinflammatory cytokines by FCPR03 may depend in part on inhibiting $\mathrm{NF}-\kappa \mathrm{B}$ p65 translocation.
Here, we have demonstrated a significant anti-inflammatory effect of FCPR03 in vitro, and this effect is probably through upregulating the cAMP/PKA/CREB signaling pathway and inhibiting the activation of NF- $\kappa \mathrm{B}$; however its anti-inflammatory effect and the responsible signaling still need to be studied in animal models.

Effect of FCPR03 on the Levels of Brain Proinflammatory Cytokines in LPS-Treated Mice. Since FCPR03 exhibited an appreciable anti-inflammatory effect in vitro, we were eager to know whether FCPR03 has a similar effect in vivo. A single systemic administration of LPS in mice is widely used as an important neuroinflammatory animal model in vivo (Khan et al., 2016). Hence, we adopted this model to evaluate the anti-inflammatory effect of FCPR03. Consistent with previous findings, the current study showed that the levels of proinflammatory cytokines (TNF- $\alpha$, IL-1 $\beta$, and IL-6) in the hippocampus and cortex were significantly increased 24 hours after parenteral administration of $1.2 \mathrm{mg} / \mathrm{kg}$ LPS $(P<0.01)$. After 7 consecutive days of administration with FCPR03 or rolipram, however, the levels of proinflammatory cytokines in the hippocampus and cortex were significantly decreased, confirming the finding that
A

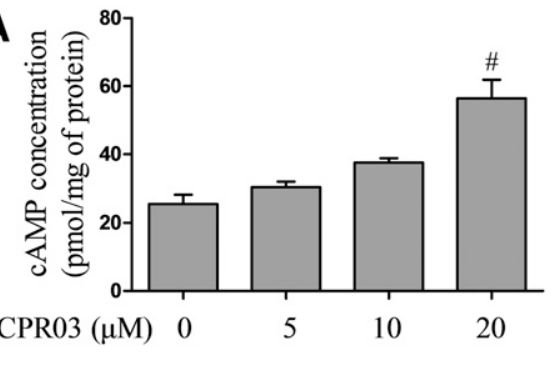

$B$

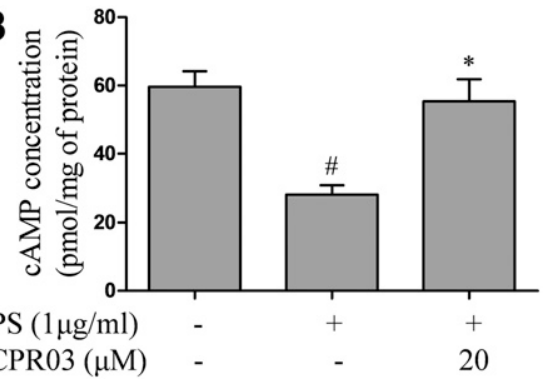

Fig. 3. FCPR03 increased the level of intracellular cAMP in BV-2 microglial cells. BV-2 microglial cells were treated with various concentrations of FCPR03 for 1 hour (A), cells were pretreated with various concentrations of FCPR03 for 1 hour and then incubated with or without LPS $(1 \mu \mathrm{g} / \mathrm{ml})$ for 24 hours (B), and intracellular cAMP concentrations were measured by ELISA. Results are shown as the mean \pm S.E.M. $(n=6 /$ group $) .{ }^{\#} P<$ 0.05 compared with the control group; $* P<0.05$ compared with the LPS group. 
A

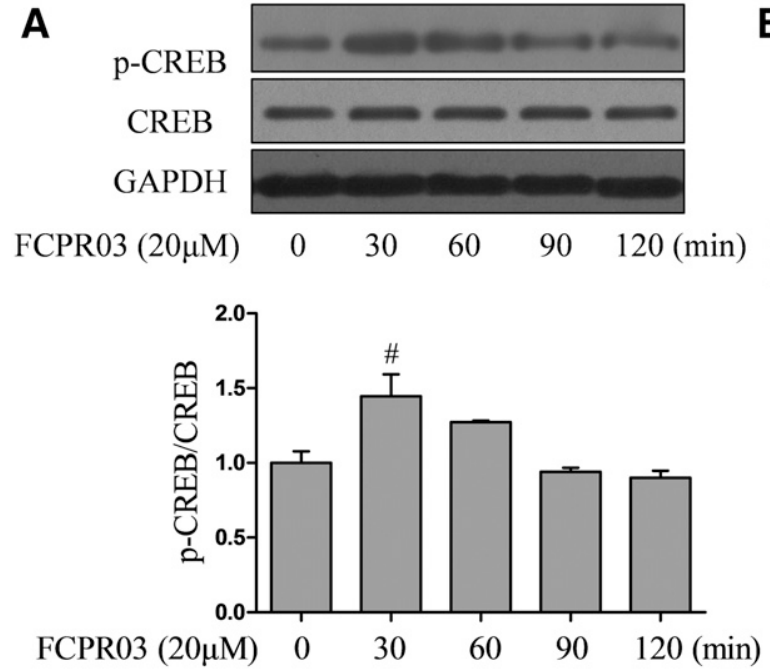

B

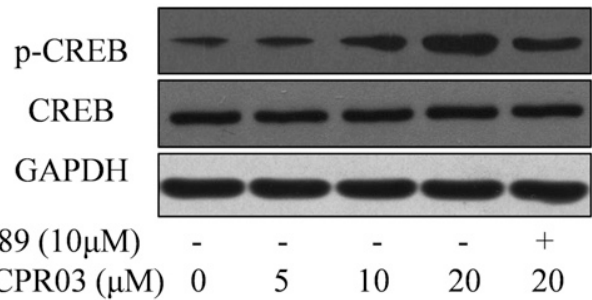

C
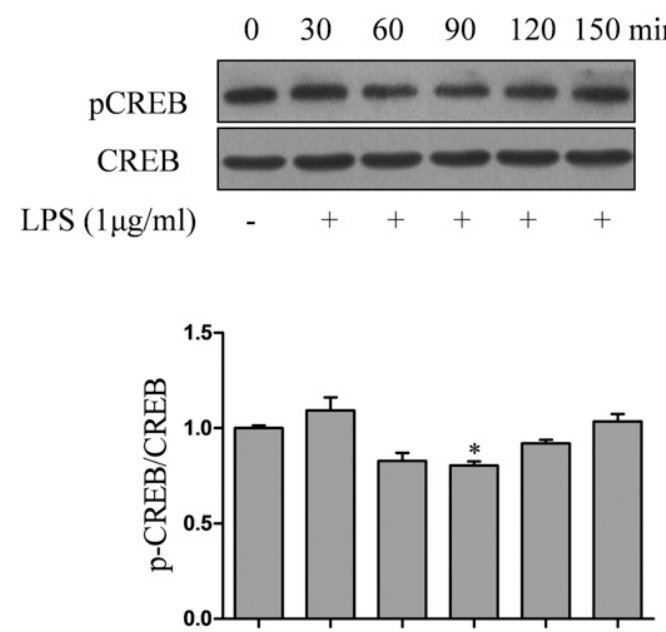

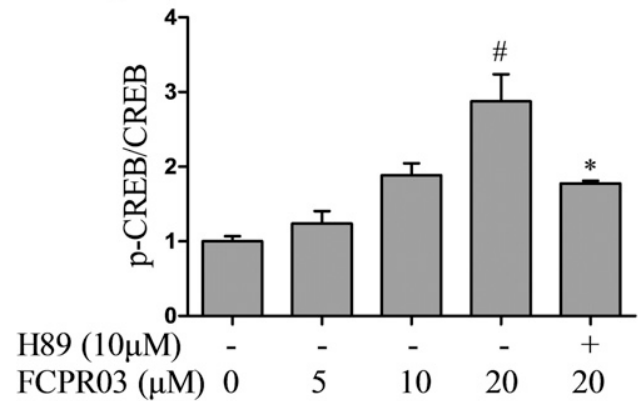

D

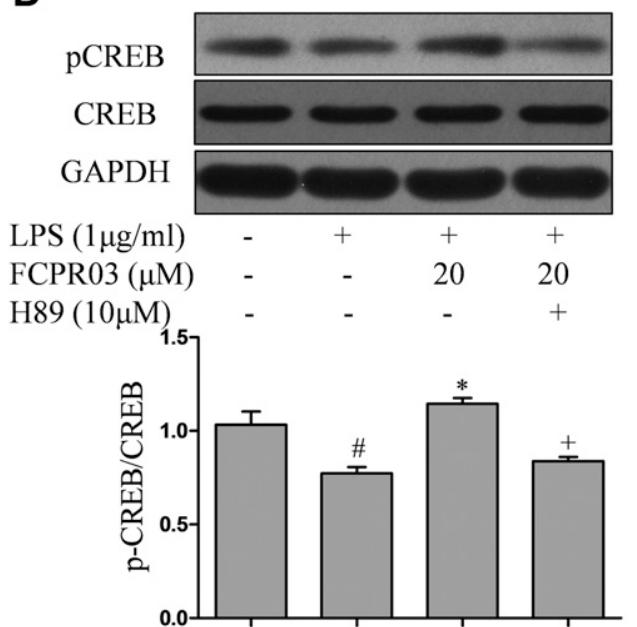

Fig. 4. FCPR03 promoted the phosphorylation of CREB in BV-2 microglial cells. BV-2 microglial cells were pretreated with $20 \mu \mathrm{M}$ of FCPR03 for the indicated times (A) or various concentrations of FCPR03 $(0,5,10$, and $20 \mu \mathrm{M})$ for 30 minutes (B). BV-2 microglial cells were pretreated with LPS $(1 \mu \mathrm{g} / \mathrm{ml})$ for the indicated times (C). After treatment of FCPR03 $(20 \mu \mathrm{M})$ for 30 minutes, BV-2 microglial cells were incubated with LPS $(1 \mu \mathrm{g} / \mathrm{ml})$ for another 90 minutes (D). Levels of phosphorylated CREB (pCREB) and total CREB were determined by Western blot. The corresponding quantification data are shown in each panel. Data are expressed as mean \pm S.E.M. $\left(n=3\right.$ /group). ${ }^{\#} P<0.05$ compared with the FCPR03 (20 $\mu$ M) group; ${ }^{*} P<0.05$ compared with the control group.

FCPR03 is a promising compound that has the property to reduce neuroinflammation (Fig. 6).

Effect of FCPRO3 on the CAMP/PKA/CREB Signaling Pathway in LPS-Treated Mice. Previous data have revealed that FCPR03 possesses a potent anti-inflammatory property in vitro via regulating the cAMP/PKA/CREB signaling pathway. We assessed whether the antineuroinflammatory effects of FCPR03 in LPS-treated mice were mediated by this signaling pathway. As shown in Fig. 7A, LPS administration significantly decreased cAMP levels both in the hippocampus and cortex compared with the control group $(P<0.01)$. As expected, FCPR03 $(1 \mathrm{mg} / \mathrm{kg})$ or rolipram $(1 \mathrm{mg} / \mathrm{kg})$ increased cAMP levels in both the hippocampus and cortex $(P<0.05)$. CREB phosphorylation in the hippocampus and cortex were dramatically decreased after LPS administration $(P<0.01)$; meanwhile, these effects were reversed by pretreatment with FCPR03 $(P<0.05)$ (Fig. 7, B and $\mathrm{C})$. In line with in vitro data, these results suggest that the anti-neuroinflammatory effects of FCPR03 may involve the cAMP/PKA/CREB signaling pathway in LPS-treated mice.
Effect of FCPR03 Pretreatment on LPS-Induced NF- $\kappa$ B Activation in Hippocampus and Cortex. To further confirm the suppressive effect of FCPR03 on LPS-induced NF- $\kappa \mathrm{B}$ activation, Western blot was performed to monitor $\mathrm{NF}-\kappa \mathrm{B}$ p65 protein expression in the hippocampus and cortex. As shown in Fig. 8, A and $\mathrm{B}$, the $\mathrm{NF}-\kappa \mathrm{B}$ p65 protein levels in the whole cells showed no significant difference in the hippocampus and cortex; however, cytoplasmic NF- $\kappa \mathrm{B}$ p 65 protein levels were markedly decreased in the LPS group, in both the hippocampus and cortex $(P<0.05)$ (Fig. 8, C and D), whereas the protein levels in the nucleus were increased markedly in both brain regions $(P<0.01)$ (Fig. 8, E and $\mathrm{F}$ ), indicating that NF- $\kappa \mathrm{B}$ p65 was activated and translocated into the nucleus 24 hours after exposure to LPS. Pretreatment with FCPR03 $(1 \mathrm{mg} / \mathrm{kg})$ inhibited the translocation of NF- $\kappa \mathrm{B}$ p65. Our results demonstrate that FCPR03 contributes to the attenuation of neuroinflammatory response probably through inhibiting $\mathrm{NF}-\kappa \mathrm{B}$ activation.

FCPR03 Alleviated the Sickness Behaviors and Cognitive Deficits in Female Mice Treated by LPS. It has been 
A
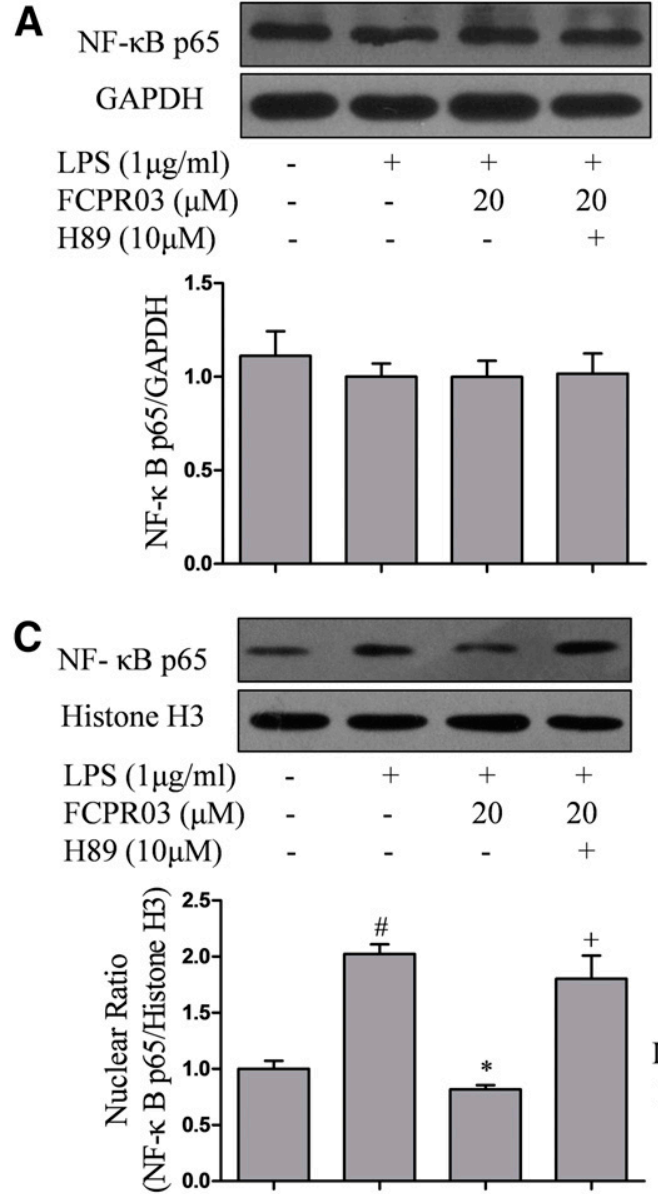

B
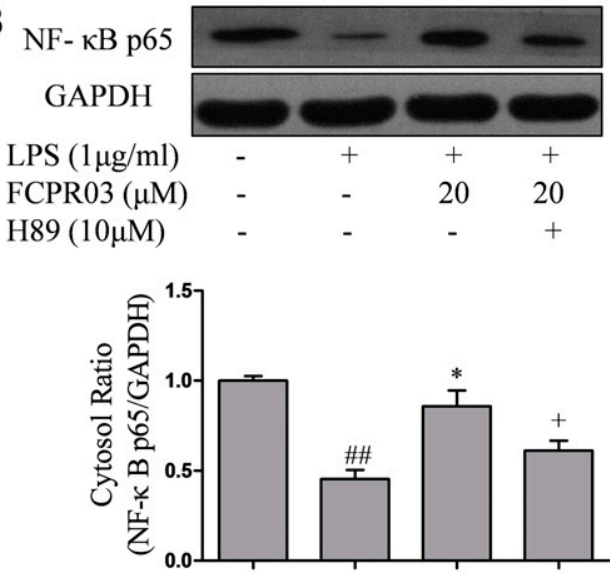

D

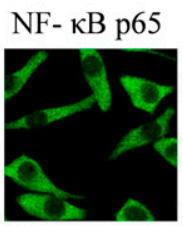

DAPI

Merged

con
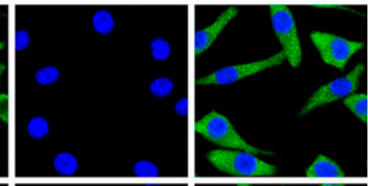

LPS $(1 \mu \mathrm{g} / \mathrm{ml})$
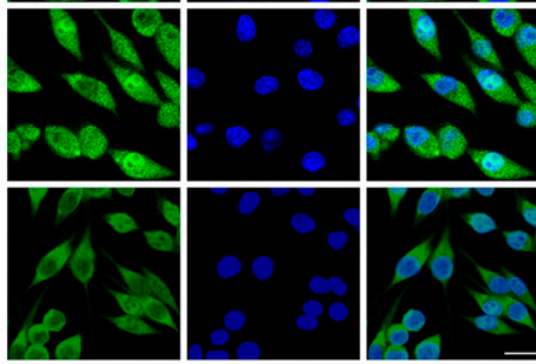

Fig. 5. Effect of FCPR03 on NF- $\kappa$ B p65 activation in LPS-stimulated BV-2 microglial cells. NF- $\kappa$ B p65 protein levels in whole cells (A), cytosolic (B), and nuclear $(\mathrm{C})$ were analyzed by Western blot. NF- $\kappa$ B p65 subunit translocation was assessed by immunofluorescence (D). Scale bars $=20 \mu \mathrm{m}$. The corresponding quantification data are shown in each panel. glyceraldehyde-3-phosphate dehydrogenase ( GAPDH) and histone H3 were used as internal controls. Data are expressed as mean \pm S.E.M. $\left(n=3\right.$ /group). ${ }^{\#} P<0.05$, \#\# $P<0.01$ compared with the control group; ${ }^{*} P<0.05$ compared with the LPStreatment group; ${ }^{+} P<0.05$ compared with the LPS + FCPR03 $(20 \mu \mathrm{M})$ group.

reported that the response of mice of different sex to LPS was different (Sorge RE et al., 2011). Female mice were more resistant to LPS than were male mice, and this effect may be related to the secretion of estrogen (Hughes EL et al., 2013). Having known that FCPR03 had a potent anti-inflammatory property in male mice, we then performed another experiment to explore
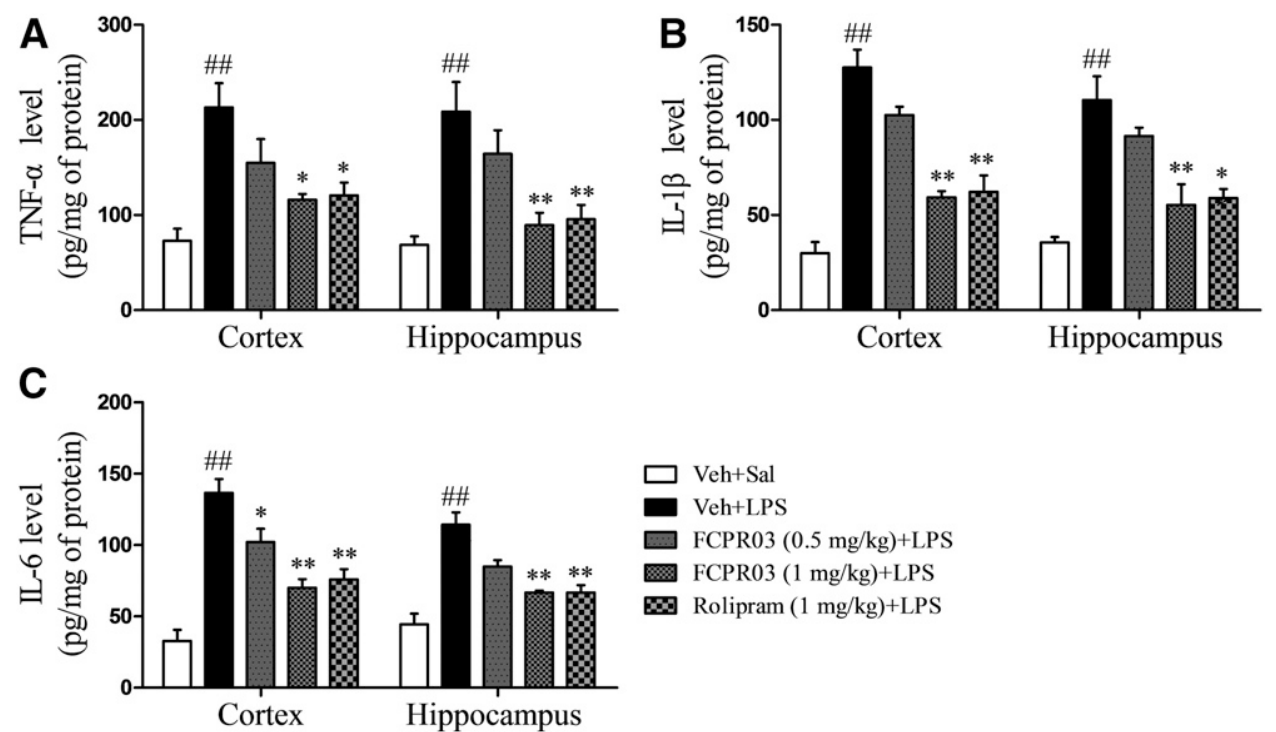

Veh+Sal
Veh+LPS
FCPR03 $(0.5 \mathrm{mg} / \mathrm{kg})+\mathrm{LPS}$
FCPR03 $(1 \mathrm{mg} / \mathrm{kg})+\mathrm{LPS}$
Rolipram $(1 \mathrm{mg} / \mathrm{kg})+\mathrm{LPS}$
Fig. 6. Effects of FCPR03 on production of LPS-induced proinflammatory cytokines in the hippocampus and cortex. After 7 consecutive days pretreatment with FCPR03 or rolipram, mice were injected i.p. with saline or $1.2 \mathrm{mg} / \mathrm{kg}$ LPS. Brains were removed 24 hours later, with the hippocampus, and the cortex was dissected and homogenized. Levels of the proinflammatory cytokines TNF- $\alpha$ (A), IL- $1 \beta$ (B), and IL-6 (C) were quantified by ELISA kits. Data are expressed as mean \pm S.E.M. $(n=$ 6-8/group). ${ }^{\# \# P}<0.01$ compared with the control group; $* P<0.05 ; * * P<0.01$ compared with the LPS group. 
A

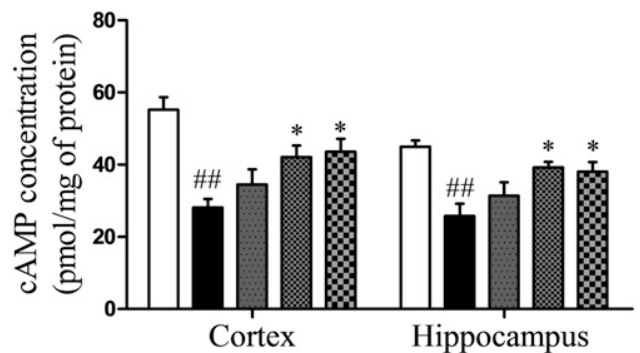

B

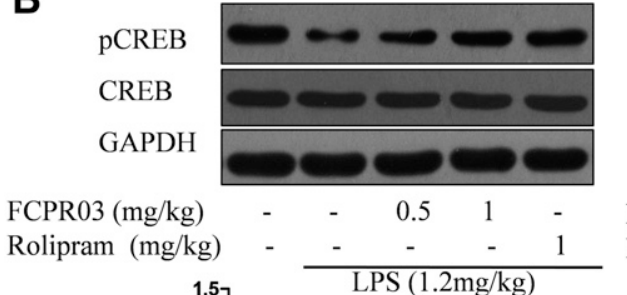

C

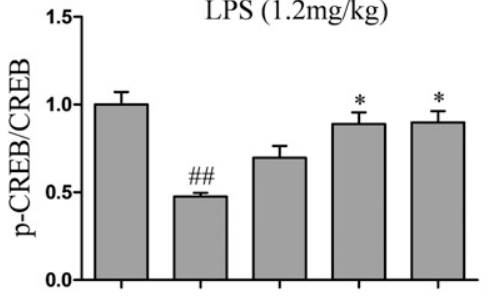

$\square \mathrm{Veh}+\mathrm{Sal}$

Veh+LPS

FCPR03 $(0.5 \mathrm{mg} / \mathrm{kg})+\mathrm{LPS}$

FCPR03 $(1 \mathrm{mg} / \mathrm{kg})+\mathrm{LPS}$

Bolipram $(1 \mathrm{mg} / \mathrm{kg})+\mathrm{LPS}$
Fig. 7. Effects of FCPR03 on the cAMP/ PKA/CREB signaling pathway in LPSinduced mice. 24 hour after LPS administration, the entire hippocampal and cortical extracts were homogenized, and cAMP levels were determined by ELISA (A). Western blot was used to assess pCREB and CREB protein levels in the cortex (B) and hippocampus (C). The corresponding quantification data are shown in each panel. Data are expressed as mean \pm S.E.M. ( $n=3$ /group).

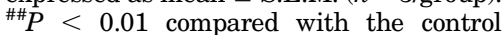
group; $* P<0.05, * * P<0.01$ compared with the LPS group. the anti-inflammatory effect of FCPR03 in female mice. As shown in Fig. 9, after 7 consecutive days of administration with $1 \mathrm{mg} / \mathrm{kg}$ FCPR03 or rolipram, the levels of cytokines in the hippocampus and cortex were significantly decreased $(P<$ 0.05); however, consistent with previous studies, we noticed that the response of female mice to LPS was weaker than that in male mice. Hence, we further investigated the alterations of sickness behaviors and cognitive deficits in female mice. Our results showed that FCPR03 significantly ameliorated the loss of appetite and cognitive deficits in female mice treated by LPS $(P<0.05)$. We also found that the body weight in mice administered FCPR03 was slightly greater than that in the LPS group, although no significant difference was observed. Taken together, our results indicate that FCPR03 possesses a potent antineuroinflammatory property in both female and male mice.

\section{Discussion}

Neuroinflammation, which is characterized by overactivation of microglia (Wes et al., 2016), is closely bound with the pathogenesis and progression of many neurodegenerative diseases (Dendrou et al., 2016; Raison et al., 2006), and inhibition of inflammation mediated by activated microglia is considered a promising approach for the treatment of these disorders (Heneka et al., 2014; Gonzalez et al., 2014). In the present study, we show for the first time that FCPR03, a selective PDE4 inhibitor, potently inhibits neuroinflammatory responses both in vitro and in vivo. Furthermore, our data demonstrate that the antineuroinflammatory effect of FCPR03 is probably mediated through the activation of the cAMP/PKA/CREB signaling pathway and NF- $\kappa \mathrm{B}$ inhibition.

Proinflammatory mediators, such as TNF- $\alpha$, IL- $1 \beta$, and IL-6, are produced after microglia activation (Rawji et al., 2016). LPS induces inflammation by activating microglia and produces various proinflammatory cytokines (Smith et al., 2012). Based on these properties, microglial cells treated with LPS are widely used as an in vitro cell model of neuroinflammation, as well as a tool for the evaluation of potential antineuroinflammatory compounds (Gupta and Kaur, 2016; Huang et al., 2016; Pfluger et al., 2016). Thus, this cell model was used in the present study to evaluate the antineuroinflammatory effect of FCPR03.

Proinflammatory cytokines exacerbate the pathology of neurodegenerative diseases and even deteriorate the processes of many brain injuries, such as traumatic brain injury and stroke. Selective PDE4 inhibitors, such as roflumilast, cilomilast, and apremilast, were reported to curb inflammatory responses both in vitro and in vivo (Buenestado et al., 2012; McLean et al., 2009). In the present study, we sought to investigate the anti-inflammatory effects of the novel PDE4 inhibitor FCPR03 both in vitro and in vivo. In line with other PDE4 inhibitors, such as apremilast (Perez-Aso et al., 2015) and GSK256066 (Grundy et al., 2016), FCPR03 can markedly inhibit the release of proinflammatory cytokines and exhibit a potent antiinflammatory property. Combined with our previous enzymatic and side effect studies on FCPR03 (Zhou et al., 2017), these data suggest that FCPR03, a PDE4 inhibitor with better selectivity and less emetic potency, has considerable anti-inflammatory activity.

cAMP, a ubiquitous second messenger, is a critical regulator of inflammatory responses, including the migration and recruitment of leukocytes, cytokine secretion, and the activation and proliferation of T cells (Mosenden and Tasken, 2011). PDE4 inhibitors, such as rolipram, produce anti-inflammatory, cognition-enhancing, and antidepressant-like effects via enhancing cAMP-mediated signaling; however, serious side effects, such as nausea and emesis, have impeded its further clinical application ( $\mathrm{Li}$ et al., 2009). Inflammatory stimulants, 
A

\section{Cortex}

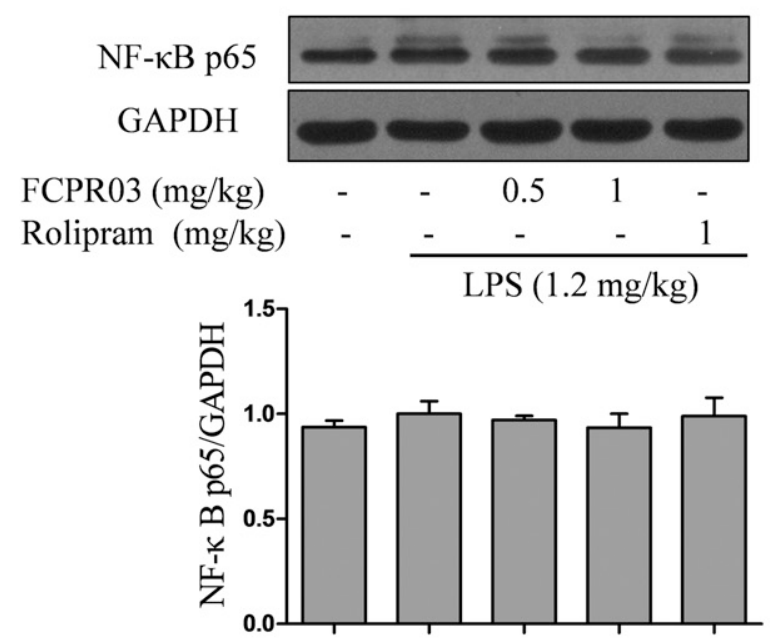

C
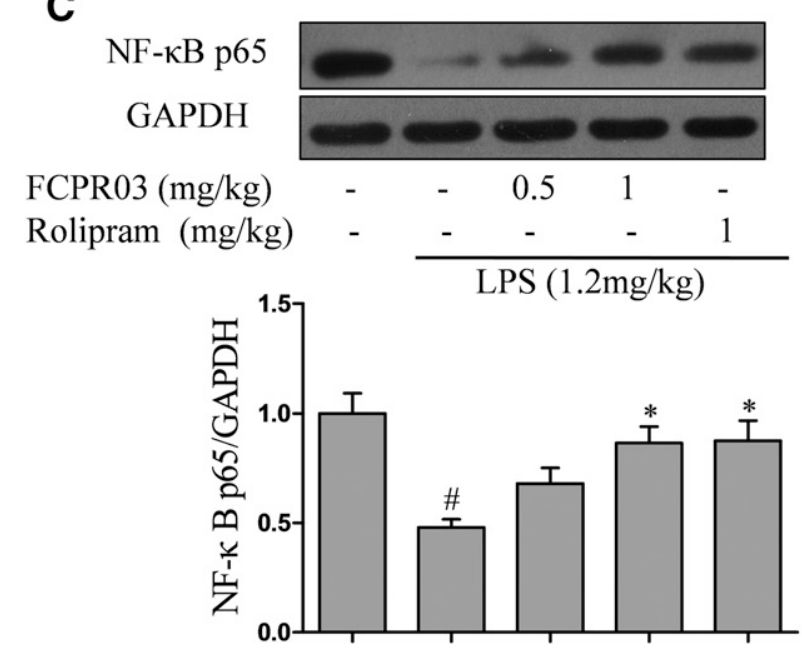

E

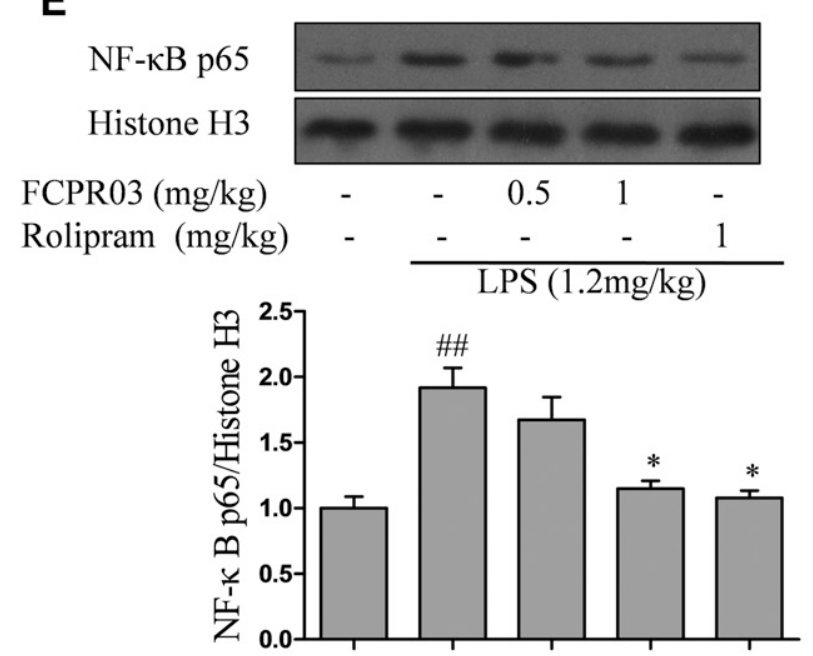

B

Hippocampus

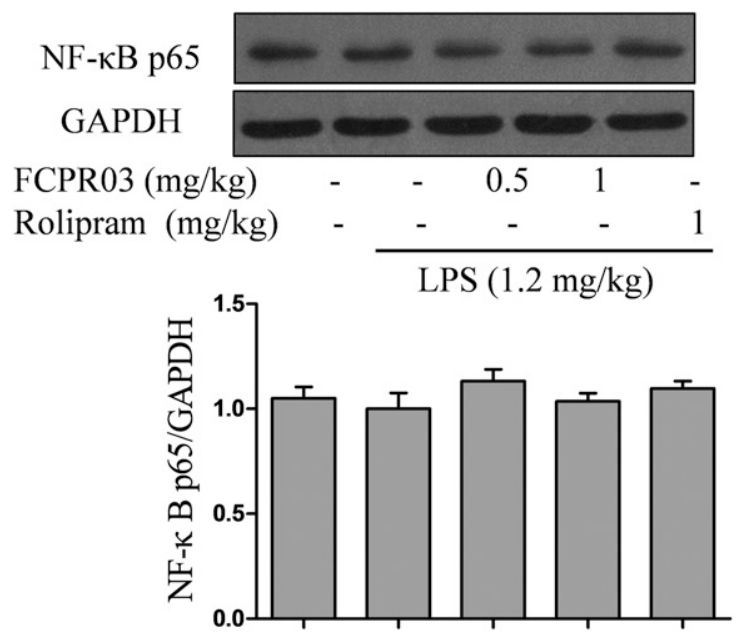

D

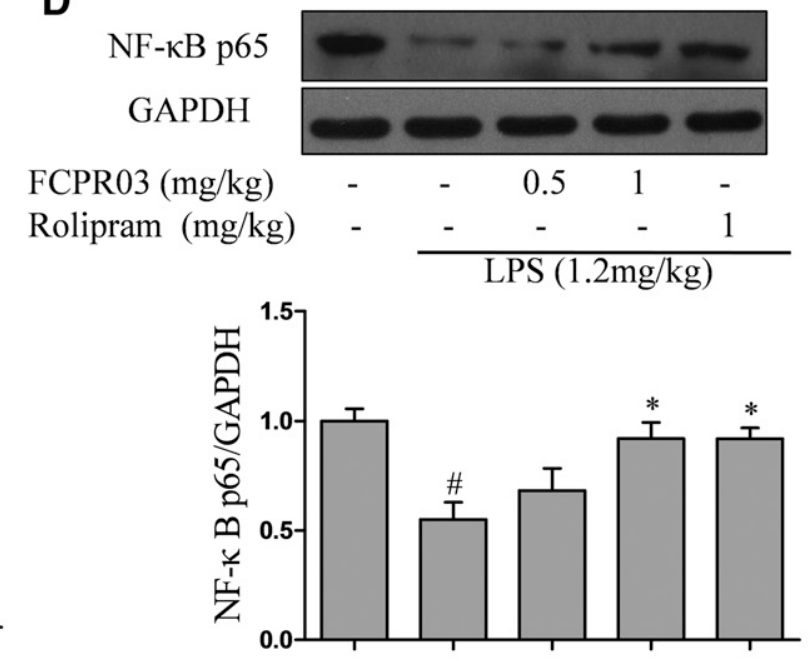

$\mathbf{F}$

\section{$\mathrm{NF}-\kappa \mathrm{B}$ p 65}

Histone $\mathrm{H} 3$

FCPR03 $(\mathrm{mg} / \mathrm{kg}) \quad-\quad-\quad \begin{array}{lllll} & 0.5 & 1 & -\end{array}$

Rolipram (mg/kg) - $\frac{-1-1}{\operatorname{LPS}(1.2 \mathrm{mg} / \mathrm{kg})}$

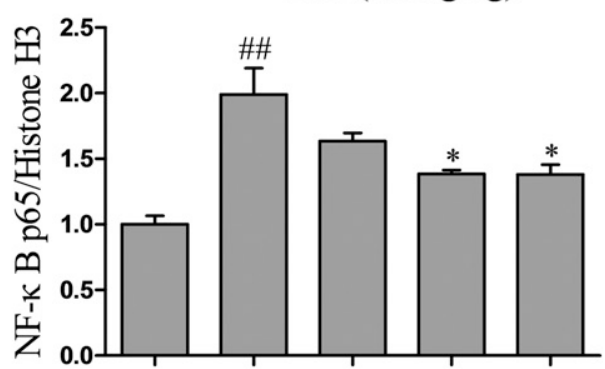

Fig. 8. Effects of FCPR03 on LPS-induced NF- $\kappa$ B activation in the hippocampus and cortex. 24 hours after LPS administration, the total NF- $\kappa$ B p65 protein levels in cortex and hippocampus were detected (A, B), and then the cytosolic and nuclear proteins in the mouse hippocampus and cortex were separated. Cytosolic NF- $\kappa$ B p65 protein levels in the cortex and hippocampus (C, D), as well as nuclear NF- $\kappa$ B p65 protein amounts in the cortex and hippocampus (E, F), were analyzed by Western blot. The corresponding quantification data are shown in each panel. Data are expressed as mean \pm S.E.M. $\left(n=3\right.$ /group). " $P<0.05$; ${ }^{\# \#} P<0.01$ compared with the control group; $* P<0.05$, compared with the LPS group. 

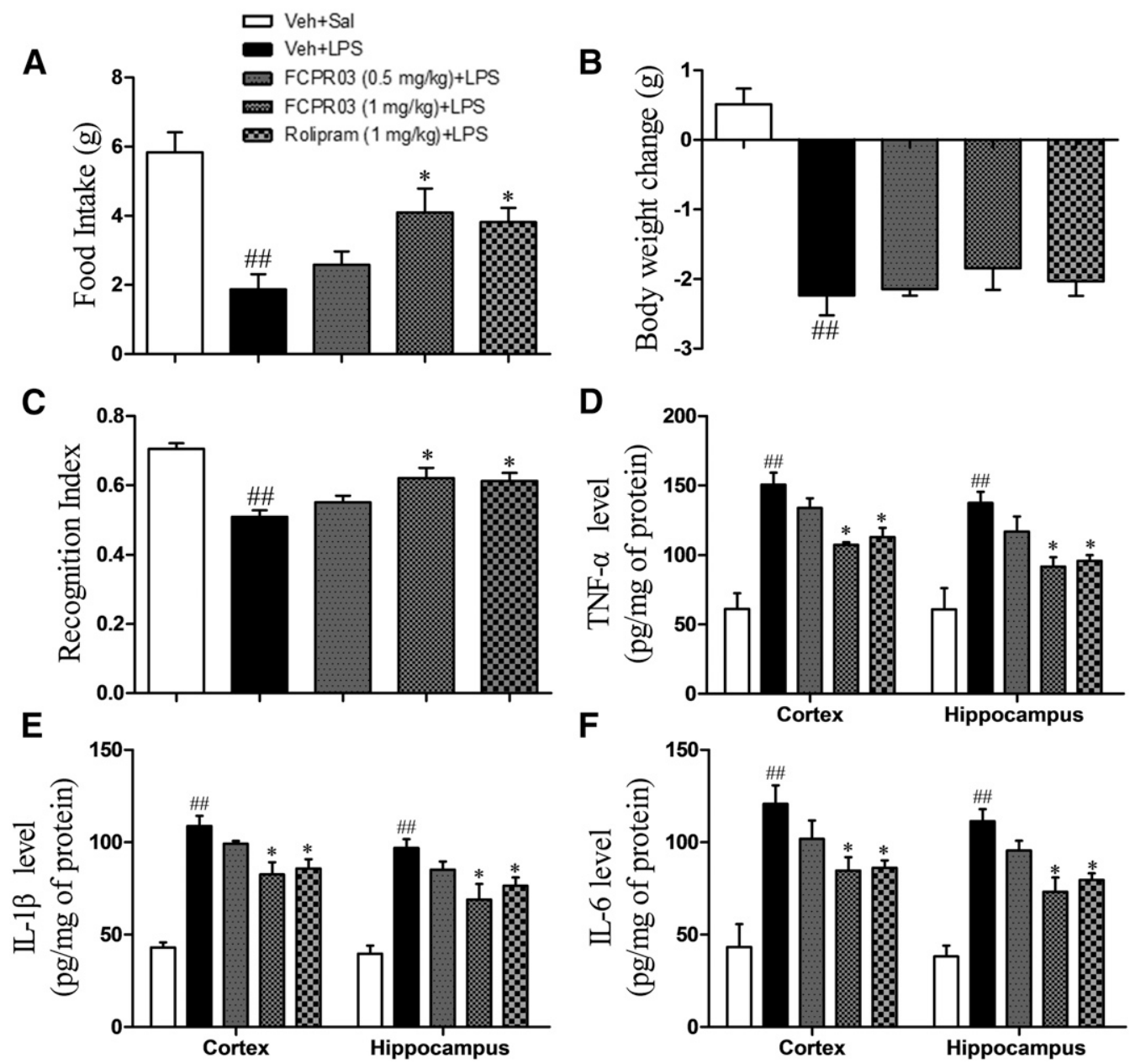

Fig. 9. FCPR03 alleviated the sickness behaviors and cognitive deficits in female mice treated with LPS. After 7 consecutive days of pretreatment with FCPR03 or rolipram, mice were injected i.p. with saline or $1.2 \mathrm{mg} / \mathrm{kg}$ LPS; 24 hours after LPS injection, food intake (A) and body weight change (B) were measured. The novel recognition test (C) was carried out, and then the hippocampus and cortex were dissected and homogenized. Levels of the proinflammatory cytokines TNF- $\alpha$ (D), IL-1 $\beta$ (E), and IL-6 (F) were quantified by ELISA assay. Data are expressed as mean \pm S.E.M. $(n=6-8 /$ group), ${ }_{\# \#} P<0.01$ compared with the control group; ${ }^{*} P<0.05$ compared with the LPS group.

including LPS, interferon (IFN)- $\gamma$, and TNF- $\alpha$, remarkably reduce the intracellular cAMP level in microglial cells, leading to changes in morphology and promoting the production of proinflammatory cytokines, whereas these changes could be reversed by PDE4 inhibitors (Ghosh et al., 2012). In accordance with this result, we found that pretreatment with FCPR03 prevented the decrease of intracellular cAMP and phosphorylated CREB levels in LPS-treated microglial cells. Furthermore, for the sake of investigating whether PKA mediates the anti-inflammatory effect of FCPR03, cells were pretreated with PKA inhibitor H89 (Zeng et al., 2016). Interestingly, the current data revealed that these effects of FCPR03 were mostly reversed by H89. Therefore, it is possible that the anti-inflammatory effect of FCPR03 is mediated through the cAMP/PKA/CREB signaling cascade.

Transcription factors, including NF- $\kappa \mathrm{B}$, are important regulators in the transcription of these inflammatory cytokines. Activating NF- $\kappa \mathrm{B}$ induced by LPS stimulates the expression of proinflammatory cytokines that aggravate inflammation, whereas inhibition of NF- $\kappa \mathrm{B}$ activation suppresses the expression of various genes, such as TNF- $\alpha$, IL-1 $\beta$, and IL-6 (Zhou et al., 2016). In normal microglial cells,
$\mathrm{NF}-\kappa \mathrm{B}$ is retained in the cytoplasm, whereas NF- $\kappa \mathrm{B}$ will translocate into nuclear after the activation of microglia challenged by LPS. Li et al. (2016) pointed out that NF- $\kappa \mathrm{B}$ is activated after LPS treatment and that activity of NF- $\kappa \mathrm{B}$ is regulated by the cAMP/PKA/NF- $\kappa$ B axis. Pretreatment with FCPR03 can significantly Psuppress NF- $\kappa$ B activation, and this effect was mostly blocked by pretreatment with H89, suggesting that the inhibition of proinflammatory cytokine release by FCPR03 is probably dependent on NF- $\kappa$ B inhibition, which is regulated by the cAMP/PKA signaling pathway.

Since the hippocampus and cortex play important roles in the regulation of memory, cognition, and emotion, we focused mainly on the neuroinflammation in these brain regions. Our previous study showed that lentiviral miRNA-mediated longform PDE4D knockdown could attenuate memory deficits in a mouse model of Alzheimer disease induced by hippocampal $\mathrm{A} \beta_{42}$ injections, and this effect was partially produced by inhibiting the neuroinflammation in the CNS (Zhang et al., 2014).

Although male mice are typically more responsive to TLR4 agonists than are female mice, our results show that the proinflammatory cytokine levels in the hippocampus and 
cortex were significantly decreased in both male and female mice. In addition, FCPR03 could dramatically alleviate sickness behaviors and improve the cognitive deficits induced by LPS, and the reduction of cAMP and pCREB in the hippocampus and cortex were reversed by pretreatment with FCPR03. As current available PDE4 inhibitors are limited by the emetic potency, FCPR03 is a promising candidate compound for inhibiting neuroinflammation and attenuating many neurodegenerative diseases associated with neuroinflammation.

To further explore the anti-inflammatory mechanisms of FCPR03, we investigated the effect of FCPR03 on the activation of the NF- $\kappa$ B. Because NF- $\kappa$ B plays a key role in the inflammatory process, suppression of NF- $\kappa$ B could inhibit LPSinduced inflammation (Seeley and Ghosh, 2016). Our data clearly show that pretreatment with FCPR03 could significantly inhibit the activation of $\mathrm{NF}-\kappa \mathrm{B}$ both in vitro and in vivo, suggesting that the antineuroinflammatory effect of FCPR03 is probably associated with inhibiting the activation of NF- $\kappa$.

In summary, FCPR03 inhibited neuroinflammation induced by LPS in BV-2 microglial cells through activating the cAMP/PKA/CREB pathway, inhibiting the translocation of $\mathrm{NF}-\kappa \mathrm{B}$, and thereby reducing the production of TNF- $\alpha$, IL- $1 \beta$, and IL-6. Furthermore, FCPR03 exerted a significant antineuroinflammatory effect in LPS-treated mice. In our study, we focused mainly on the alterations of inflammatory indicators and the signaling pathways involved in the role of FCPR03. Because inflammation participates in the behavioral changes in animals under the condition of stress, behavioral tests, such as assessments on learning and memory, depression, and anxiety warrant future investigations. Additionally, it would be interesting to determine the sex-specific differences in PDE4 expression and activity and TLR4 activation in this model; whether there is any difference in their response to FCPR03 needs to be studied. On the other hand, the data presented here are obtained from LPS-induced cell and animal models, but the anti-inflammatory effect of FCPR03 still needs to be confirmed in other animal models, such as in Alzheimer disease and animal models of depression. Taken together, these results reveal that FCPR03 possesses antineuroinflammatory property, strongly suggesting its potential as a candidate drug for the treatment of diseases associated with neuroinflammation.

\section{Authorship Contributions}

Participated in research design: Zou, Cheng, Wang, Xu.

Conducted experiments: Zou, Chen.

Contributed new reagents or analytic tools: Zhou.

Performed data analysis: Zou, Feng, Guo.

Wrote or contributed to the writing of the manuscript: Zou, Cheng, Wang, Zheng, Xu.

\section{References}

Blandini F (2013) Neural and immune mechanisms in the pathogenesis of Parkinson's disease. J Neuroimmune Pharmacol 8:189-201.

Brenner D, Blaser H, and Mak TW (2015) Regulation of tumour necrosis factor signalling: live or let die. Nat Rev Immunol 15:362-374.

Buenestado A, Grassin-Delyle S, Guitard F, Naline E, Faisy C, Israël-Biet D, Sage E, Bellamy JF, Tenor H, and Devillier P (2012) Roflumilast inhibits the release of chemokines and TNF- $\alpha$ from human lung macrophages stimulated with lipopolysaccharide. Br J Pharmacol 165:1877-1890.

Czeh M, Gressens P, and Kaindl AM (2011) The yin and yang of microglia. Dev Neurosci 33:199-209.

Dendrou CA, McVean G, and Fugger L (2016) Neuroinflammation - using big data to inform clinical practice. Nat Rev Neurol 12:685-698.

Eikelenboom P, Hoozemans JJ, Veerhuis R, van Exel E, Rozemuller AJ, and van Gool WA (2012) Whether, when and how chronic inflammation increases the risk of developing late-onset Alzheimer's disease. Alzheimers Res Ther 4:15.
Gauvreau GM, Boulet LP, Schmid-Wirlitsch C, Côté J, Duong M, Killian KJ, Milot J, Deschesnes F, Strinich T, Watson RM, et al. (2011) Roflumilast attenuates allergen-induced inflammation in mild asthmatic subjects. Respir Res 12:140.

Ghosh M, Garcia-Castillo D, Aguirre V, Golshani R, Atkins CM, Bramlett HM, Dietrich WD, and Pearse DD (2012) Proinflammatory cytokine regulation of cyclic AMP-phosphodiesterase 4 signaling in microglia in vitro and following CNS injury. Glia 60:1839-1859.

Gong B, Vitolo OV, Trinchese F, Liu S, Shelanski M, and Arancio O (2004) Persistent improvement in synaptic and cognitive functions in an Alzheimer mouse model after rolipram treatment. $J$ Clin Invest 114:1624-1634.

González H, Elgueta D, Montoya A, and Pacheco R (2014) Neuroimmune regulation of microglial activity involved in neuroinflammation and neurodegenerative diseases. J Neuroimmunol 274:1-13.

González-García C, Bravo B, Ballester A, Gómez-Pérez R, Eguiluz C, Redondo M, Martínez A, Gil C, and Ballester S (2013) Comparative assessment of PDE 4 and 7 inhibitors as therapeutic agents in experimental autoimmune encephalomyelitis. Br J Pharmacol 170:602-613.

Grundy S, Plumb J, Kaur M, Ray D, and Singh D (2016) Additive anti-inflammatory effects of corticosteroids and phosphodiesterase-4 inhibitors in COPD CD8 cells. Respir Res 17:9.

Gupta M and Kaur G (2016) Aqueous extract from the Withania somnifera leaves as a potential anti-neuroinflammatory agent: a mechanistic study. $J$ Neuroinflammation 13:193.

Heneka MT, Kummer MP, and Latz E (2014) Innate immune activation in neurodegenerative disease. Nat Rev Immunol 14:463-477.

Huang HY, Chang HF, Tsai MJ, Chen JS, and Wang MJ (2016) 6-Mercaptopurine attenuates tumor necrosis factor- $\alpha$ production in microglia through Nur77mediated transrepression and PI3K/Akt/mTOR signaling-mediated translational regulation. $J$ Neuroinflammation 13:78.

Hughes EL, Cover PO, Buckingham JC, and Gavins FN (2013) Role and interactions of annexin A1 and oestrogens in the manifestation of sexual dimorphisms in cerebral and systemic inflammation. Br J Pharmacol 169:539-553.

Ikemura T, Schwarze J, Makela M, Kanehiro A, Joetham A, Ohmori K, and Gelfand EW (2000) Type 4 phosphodiesterase inhibitors attenuate respiratory syncytial virus-induced airway hyper-responsiveness and lung eosinophilia. J Pharmacol Exp Ther 294:701-706.

Kaushal V, Dye R, Pakavathkumar P, Foveau B, Flores J, Hyman B, Ghetti B, Koller $\mathrm{BH}$, and LeBlanc AC (2015) Neuronal NLRP1 inflammasome activation of Caspase-1 coordinately regulates inflammatory interleukin-1-beta production and axonal degeneration-associated Caspase-6 activation. Cell Death Differ 22: $1676-1686$

Khan MS, Ali T, Kim MW, Jo MH, Jo MG, Badshah H, and Kim MO (2016) Anthocyanins protect against LPS-induced oxidative stress-mediated neuroinflammation and neurodegeneration in the adult mouse cortex. Neurochem Int 100:1-10.

Kim BW, Koppula S, Kumar H, Park JY, Kim IW, More SV, Kim IS, Han SD, Kim SK, Yoon SH, et al. (2015) $\alpha$-Asarone attenuates microglia-mediated neuroinflammation by inhibiting NF kappa B activation and mitigates MPTP-induced behavioral deficits in a mouse model of Parkinson's disease. Neuropharmacology 97:46-57.

Kopitar-Jerala N (2015) Innate immune response in brain, NF-kappa B signaling and cystatins. Front Mol Neurosci 8:73.

Li X, He S, Li R, Zhou X, Zhang S, Yu M, Ye Y, Wang Y, Huang C, and Wu M (2016) Pseudomonas aeruginosa infection augments inflammation through miR-301b repression of c-Myb-mediated immune activation and infiltration. Nat Microbiol 1:16132.

Li YF, Huang Y, Amsdell SL, Xiao L, O’Donnell JM, and Zhang HT (2009) Antidepressant- and anxiolytic-like effects of the phosphodiesterase-4 inhibitor rolipram on behavior depend on cyclic AMP response element binding proteinmediated neurogenesis in the hippocampus. Neuropsychopharmacology 34:2404-2419.

Maes M, Yirmyia R, Noraberg J, Brene S, Hibbeln J, Perini G, Kubera M, Bob P, Lerer B, and Maj M (2009) The inflammatory \& neurodegenerative (I\&ND) hypothesis of depression: leads for future research and new drug developments in depression. Metab Brain Dis 24:27-53.

McGeer PL and McGeer EG (2013) The amyloid cascade-inflammatory hypothesis of Alzheimer disease: implications for therapy. Acta Neuropathol 126:479-497.

McGirr A, Lipina TV, Mun HS, Georgiou J, Al-Amri AH, Ng E, Zhai D, Elliott C, Cameron RT, Mullins JG, et al. (2016) Specific inhibition of phosphodiesterase-4B results in Anxiolysis and facilitates wmemory acquisition. Neuropsychopharmacology 41:1080-1092.

McLean JH, Smith A, Rogers S, Clarke K, Darby-King A, and Harley CW (2009) A phosphodiesterase inhibitor, cilomilast, enhances cAMP activity to restore conditioned odor preference memory after serotonergic depletion in the neonate rat. Neurobiol Learn Mem 92:63-69.

Mosenden R and Taskén K (2011) Cyclic AMP-mediated immune regulation-overview of mechanisms of action in T cells. Cell Signal 23:1009-1016.

Neher JJ, Emmrich JV, Fricker M, Mander PK, Théry C, and Brown GC (2013) Phagocytosis executes delayed neuronal death after focal brain ischemia. Proc Natl Acad Sci USA 110:E4098-E4107.

Norden DM, Trojanowski PJ, Villanueva E, Navarro E, and Godbout JP (2016) Sequential activation of microglia and astrocyte cytokine expression precedes increased Iba-1 or GFAP immunoreactivity following systemic immune challenge. Glia 64:300-316.

Pais TF, Szegő EM, Marques O, Miller-Fleming L, Antas P, Guerreiro P, de Oliveira RM, Kasapoglu B, and Outeiro TF (2013) The NAD-dependent deacetylase sirtuin 2 is a suppressor of microglial activation and brain inflammation. EMBO J 32:2603-2616.

Papp K, Cather JC, Rosoph L, Sofen H, Langley RG, Matheson RT, Hu C, and Day RM (2012) Efficacy of apremilast in the treatment of moderate to severe psoriasis: a randomised controlled trial. Lancet 380:738-746.

Perez-Aso M, Montesinos MC, Mediero A, Wilder T, Schafer PH, and Cronstein B (2015) Apremilast, a novel phosphodiesterase 4 (PDE4) inhibitor, regulates inflammation through multiple cAMP downstream effectors. Arthritis Res Ther 17:249. 
Pflüger P, Viau CM, Coelho VR, Berwig NA, Staub RB, Pereira P, and Saffi J (2016) Gamma-decanolactone inhibits iNOS and TNF-alpha production by lipopolysaccharideactivated microglia in N9 cells. Eur J Pharmacol 780:38-45.

Philips T and Robberecht W (2011) Neuroinflammation in amyotrophic lateral sclerosis: role of glial activation in motor neuron disease. Lancet Neurol 10:253-263.

Plattner F, Hayashi K, Hernández A, Benavides DR, Tassin TC, Tan C, Day J, Fina MW, Yuen EY, Yan Z, et al. (2015) The role of ventral striatal cAMP signaling in stress-induced behaviors. Nat Neurosci 18:1094-1100.

Raison CL, Capuron L, and Miller AH (2006) Cytokines sing the blues: inflammation and the pathogenesis of depression. Trends Immunol 27:24-31.

Rawji KS, Mishra MK, Michaels NJ, Rivest S, Stys PK, and Yong VW (2016) Immunosenescence of microglia and macrophages: impact on the ageing central nervous system. Brain 139:653-661.

Rothaug M, Becker-Pauly C, and Rose-John S (2016) The role of interleukin-6 signaling in nervous tissue. Biochim Biophys Acta 1863 (6 Part A):1218-1227.

Schett G, Wollenhaupt J, Papp K, Joos R, Rodrigues JF, Vessey AR, Hu C, Stevens R and de Vlam KL (2012) Oral apremilast in the treatment of active psoriatic arthritis: results of a multicenter, randomized, double-blind, placebo-controlled study. Arthritis Rheum 64:3156-3167.

Seeley JJ and Ghosh S (2017) Molecular mechanisms of innate memory and tolerance to LPS. J Leukoc Biol 101:107-119.

Smith JA, Das A, Ray SK, and Banik NL (2012) Role of pro-inflammatory cytokines released from microglia in neurodegenerative diseases. Brain Res Bull 87:10-20.

Sorge RE, LaCroix-Fralish ML, Tuttle AH, Sotocinal SG, Austin JS, Ritchie J, Chanda ML, Graham AC, Topham L, Beggs S, et al. (2011) Spinal cord Toll-like receptor 4 mediates inflammatory and neuropathic hypersensitivity in male but not female mice. J J Neurosci 31:15450-15454.

Wang C, Yang XM, Zhuo YY, Zhou H, Lin HB, Cheng YF, Xu JP, and Zhang HT (2012) The phosphodiesterase-4 inhibitor rolipram reverses $A \beta$-induced cognitive impairment and neuroinflammatory and apoptotic responses in rats. Int $\mathrm{J} \mathrm{Neu}$ ropsychopharmacol 15:749-766.

Wang G, Chen L, Pan X, Chen J, Wang L, Wang W, Cheng R, Wu F, Feng X, Yu Y, et al. (2016) The effect of resveratrol on beta amyloid-induced memory impairment involves inhibition of phosphodiesterase-4 related signaling. Oncotarget 7:17380-17392.
Wes PD, Holtman IR, Boddeke EW, Möller T, and Eggen BJ (2016) Next generation transcriptomics and genomics elucidate biological complexity of microglia in health and disease. Glia 64:197-213.

Wilms H, Rosenstiel P, Sievers J, Deuschl G, Zecca L, and Lucius R (2003) Activation of microglia by human neuromelanin is NF-kappaB dependent and involves p38 mitogen-activated protein kinase: implications for Parkinson's disease. FASEB $J$ 17:500-502.

Yuan L, Liu S, Bai X, Gao Y, Liu G, Wang X, Liu D, Li T, Hao A, and Wang Z (2016) Oxytocin inhibits lipopolysaccharide-induced inflammation in microglial cells and attenuates microglial activation in lipopolysaccharide-treated mice. J Neuroinflammation 13:77.

Zeng B, Li Y, Niu B, Wang X, Cheng Y, Zhou Z, You T, Liu Y, Wang H, and Xu J (2016) Involvement of PI3K/Akt/FoxO3a and PKA/CREB signaling pathways in the protective effect of fluoxetine against corticosterone-induced cytotoxicity in PC12 Cells. J Mol Neurosci 59:567-578.

Zhang C, Cheng Y, Wang H, Wang C, Wilson SP, Xu J, and Zhang HT (2014) RNA interference-mediated knockdown of long-form phosphodiesterase-4D (PDE4D) enzyme reverses amyloid- $\beta 42$-induced memory deficits in mice. J Alzheimers Dis 38:269-280.

Zhou Y, Wu Z, Cao X, Ding L, Wen Z, and Bian JS (2016) HNO suppresses LPSinduced inflammation in BV-2 microglial cells via inhibition of NF-кB and p38 MAPK pathways. Pharmacol Res 111:885-895.

Zhou Z, Cheng Y, Zou Z, Ge B, Yu H, Huang C, Wang H, Yang X, and Xu J (2017) Discovery of $\mathrm{N}$-alkyl catecholamides as selective phosphodiesterase-4 inhibitor with anti-neuroinflammation potential exhibiting antidepressant-like effects at non-emetic doses. ACS Chem Neurosci 8:135-146.

Address correspondence to: Dr. Jiang-Ping Xu, Department of Neuropharmacology and Novel Drug Discovery, School of Pharmaceutical Sciences, Southern Medical University, Guangzhou 510515, China. E-mail: jpx@smu. edu.cn. 